\title{
XXVI. Correction in a paper published in the Philosophical Magazine for January
}

\section{G.B. Airy Esq. M.A. F.R.S.}

To cite this article: G.B. Airy Esq. M.A. F.R.S. (1841) XXVI. Correction in a paper published in the Philosophical Magazine for January, Philosophical Magazine Series 3, 18:115, 132-133, DOI: 10.1080/14786444108650261

To link to this article: http://dx.doi.org/10.1080/14786444108650261

册 Published online: 01 Jun 2009.

Submit your article to this journal $[\pi$

Џll Article views: 6

Q View related articles $₫$ 
The pressure $p_{1}$ corresponding to $\theta=\frac{\pi}{2}$ is that part which is common to every point of the surface of the sphere. Hence the pressure which tends to put the sphere in motion, or $p-p_{,}$, is

\section{$b m r \cos \theta \cos b t$.}

This, by the remark made at the commencement of the reasoning, is the same pressure as when the fluid is stationary and the sphere in motion, and is identical, if very small quantities be neglected, with the value obtained by a very different process at the bottom of p. 465 of my communication to the December Number. The consideration of the lateral pressure does not therefore lead to any variation from the former result.

The force of this explanation will, perhaps, be more clearly seen by the following remark. Supposing the sphere at rest and the fluid in motion, the velocity at the position corresponding to $\theta=0$ is nothing. But as the lines drawn at any instant in the direction of the motion of the particles through which they pass nowhere intersect the surface of the sphere, it follows that the particles about that position are successively carried along the surface till at a position corresponding to $\theta=\frac{\pi}{2}$ they acquire the velocity of the stream. The lateral pressure is concerned in effecting this transfer of the individual particles, while the law of its variation at any instant along the surface of the sphere is that which is given by the preceding investigation. When the fluid is at rest and the sphere in motion the velocity impressed on any particle at the position $\theta=0$ is reduced to nothing when it arrives at the position $\theta=\frac{\pi}{2}$ by the same pressure.

I am, Gentlemen, yours, \&c.

Cambridge Observatory, Jan. 18, 1841.

J. Challis.

XXVI. Correction in a paper published in the Philosophical Magazine for January. By G. B. Aır, Esq., M.A., F.R.S., Astronomer Royal.

To the Editors of the Philosophical Magazine and Journal.

Gentlemen,

T AM indebted to the kindness of Mr. Tovey for pointing

1 out an omission in my investigation published in your Number for January; arising, as will frequently happen, from the difficulty of attending to every small step when hastily 
Mr.W.G. Armstrong on the Electricity of Expanding Air. 133 writing out an investigation with whose results we are familiar.

I request you to insert in your February Number the following correction :

Philosophical Magazine, January 1841, page 9, line 6, read as follows:

"Here $a=0$, and the approximate investigation for $r_{1}$ at the bottom of page 3, does not apply. Remarking, however; that $r_{i}$ is now $=0$, the expression for $\frac{2 \pi}{\lambda} \sqrt{h^{2}+r_{i}^{2}}$ is reduced to $\frac{2 \pi}{\lambda} h+0:$ the term corresponding to $\cos \left(e_{1} \cos \theta\right)$ is $\cos 0$ or 1 : and the term corresponding to $\frac{1}{2 \pi} \int_{\theta}\left(\cos e_{1}\right.$ $\cos \theta$ ) (from 0 to $2 \pi$ ) is $\frac{1}{2 \pi} \times 2 \pi=1$. The expression for the intensity therefore becomes $1+\mathrm{E}^{2} / \pi^{\prime \prime}$

No alteration is required after line 7 , and the results of the investigation are in no way affected.

I am, Gentlemen, yours, \&c.

Royal Observatory, Greenwich,

G. B. AlRy. Jan. 20,1841 .

XXVII. On the Electricity of expanding Air, as connected with the Electrical Phanomena of Effluent Steam. By WM. Geo. Armatrong, Esq.

To the Editors of the Philosophical Magazine and Journal. Gentlemen,

IN connexion with the experiments which $I$ have recently published on the electricity of effluent steam, it occurred to me that it would be well to inquire whether similar effects to those I have described, could be produced by compressing common air in a receiver, and then suffering it to escape in a jet, in the same manner as steam had been discharged from a boiler in the experiments alluded to. With this view, therefore, I condensed about eight atmospheres into a strong vessel, the capacity of which was nearly six quarts; I then insulated the vessel, and discharged the air through a glass tube which I had previously inserted for the purpose.

On the first trial I obtained no indications of electricity whatever, but upon repeating the experiment on a subsequent day, the insulated vessel became so highly electrified, when 